Check for updates

Cite this: RSC Adv., 2018, 8, 35327

Received 7th August 2018

Accepted 26th September 2018

DOI: $10.1039 / c 8 r a 06656 f$

rsc.li/rsc-advances

\section{Pristine carbon nitride as active material for high- performance metal-free supercapacitors: simple, easy and cheap $\uparrow$}

\author{
Roger Gonçalves, ${ }^{a}$ Thiago M. Lima, ${ }^{\text {bc }}$ Márcio W. Paixão (D) \\ and Ernesto C. Pereira (iD *a
}

\begin{abstract}
Understanding the basic properties of pristine carbon nitride electrodes is of great importance for their further applications as supercapacitor materials. To this end, a comparative study of unmodified carbon nitride is crucial to understand the difference between the bare material and its composite counterparts described in the literature. Therefore, the aim of this paper is to explore the electrochemical behaviour of casting-produced $\mathrm{C}_{3} \mathrm{~N}_{4}$ electrodes using cyclic voltammetry, charge/discharge curves and impedance spectroscopy. The results from this study show a capacitance value of $113.7 \mathrm{~F} \mathrm{~g}^{-1}$ at $0.2 \mathrm{~A} \mathrm{~g}^{-1}$ with an impressive retention of $89.2 \%$ after 5000 charge and discharge cycles at $3.0 \mathrm{~A} \mathrm{~g}^{-1}$. In addition, this material shows a large amount of specific energy $\left(76.5 \mathrm{~W} \mathrm{~h} \mathrm{~kg}^{-1}\right)$ at an operation power of $11.9 \mathrm{~W} \mathrm{~kg}^{-1}$, decreasing only $10.7 \%$ due to the electrochemical aging process. Hence, $\mathrm{C}_{3} \mathrm{~N}_{4}$ constitutes a long-life pristine material with a large amount of energy and a moderate operation power with better performance than other $\mathrm{C}_{3} \mathrm{~N}_{4}$-based composites found in the literature. These results are important to gain a better understanding of the inherent properties of carbon nitride - to further design composites with higher specific capacitance, longer lifetime, and specific energy.
\end{abstract}

\section{Introduction}

Because of the dramatic increase in the use of fossil fuels and the global concerns about the depletion of natural resources, there has been strong new interest in new renewable energy sources such as wind and solar energy ${ }^{1}$ to replace the use of fossil fuels in global energy consumption. Since wind and solar power generation is intermittent and variable, the search for new energy storage devices with greater storage and recovery capacity is one of the most important research topics in sustainable energy sources. Thus nanostructured materials are important for the development of such devices ${ }^{2,3}$ due to their unique properties. Mainly used to supply a large energy amount in a short time, capacitors are used in diverse electronic equipment. ${ }^{4}$ Supercapacitors can provide hundreds of times more power in the same volume compared with conventional capacitors, and additionally they have been developed using

${ }^{a}$ Center for the Development of Functional Materials (CDMF), Department of Chemistry, Federal University of São Carlos, Mail Box 676, CEP 13565-905, São Carlos, SP, Brazil. E-mail: ernesto@ufscar.br

${ }^{b}$ Inorganic Chemistry Department, Federal Fluminense University, CEP 24020-150, Niterói, RJ, Brazil

${ }^{c}$ Center of Excellence for Research in Sustainable Chemistry (CERSusChem), Department of Chemistry, Federal University of São Carlos, Mail Box 676, CEP 13565-905, São Carlos, SP, Brazil

$\dagger$ Electronic supplementary information (ESI) available. See DOI: 10.1039/c8ra06656f different materials when compared to the conventional ones. Two different kinds of capacitance are expected for supercapacitors: double-layer capacitance and the pseudocapacitance due to an electrochemical reaction. ${ }^{5}$ Moreover, supercapacitors are capable of managing high power rates compared to batteries $^{4}$ and it is noteworthy to mention that these materials are an attractive and plausible alternative for renewable energy applications in electric vehicles.

Organic materials are very interesting and allow further improvements in existing energy storage technologies. It is important to emphasise that organic materials are abundant, cheap, and their synthesis can be designed to produce minimal waste. Furthermore, these materials are very versatile and allow various types of functionalization to improve their properties. ${ }^{6}$ Graphene-based supercapacitors are well researched due to interesting properties of graphene oxide (GO) and reduced graphene oxide (rGO). ${ }^{7}$ Among them, Wang et al. ${ }^{8}$ reported the synthesis of $\mathrm{Ni}(\mathrm{OH})_{2}$ nanoplates supported on graphene sheets - this new material showed a surprising capacitance value of $1335 \mathrm{~F} \mathrm{~g}^{-1}$ at a current density of $2.8 \mathrm{~A} \mathrm{~g}^{-1}$ with a retention of $\sim 99 \%$ after 2000 charge/discharge cycles at $28.6 \mathrm{~A} \mathrm{~g}^{-1}$. On the other hand, using another synthetic method and bare GO, Lee et $a l .{ }^{9}$ produced nanoballs of a mesoporous grapheme using chemical vapour deposition with a high specific area $\left(508 \mathrm{~m}^{2}\right.$ $\left.\mathrm{g}^{-1}\right)$ and this material exhibited a capacitance value of $206 \mathrm{~F} \mathrm{~g}^{-1}$ with an excellent retention of $97 \%$ after $10 \mathrm{k}$ cycles. Although graphene has presented such interesting remarks, its synthesis 
in high purity possesses some drawbacks e.g., multistep synthesis and hazardous waste generation that is highly acid and oxidant. ${ }^{7}$ In this context, the research for new graphene-like materials with similar properties and environmentally friendly has been one of the most important topics over the last few years.

It is also important to cite some works in which planar-like materials was used as supercapacitor active material. This kind of structures have shown an improved performance due to, among other factors, the interlayer intercalation. ${ }^{10,11}$ Besides, the enhanced operation life-time could be archived with the use of large molecules between the $2 \mathrm{D}$ structures of the material of interest. $^{\text {12,13 }}$

Although g- $\mathrm{C}_{3} \mathrm{~N}_{4}$ was discovered in $1834,{ }^{14}$ research and application of its properties began only in 2006, with the detection of its photocatalytic properties for hydrogen evolution. ${ }^{15}$ Its structure is based on heptazine units, which exhibit different properties and reactivity depending on its synthesis conditions. $\mathrm{g}-\mathrm{C}_{3} \mathrm{~N}_{4}$ is a metal-free polymeric conjugated semiconductor that can be easily obtained by thermal polymerization of nitrogen rich precursors such as melamine, dicyandiamide, cyanamide, urea, thiourea, and ammonium thiocyanate. ${ }^{16}$ Each of these precursors leads to $\mathrm{C}_{3} \mathrm{~N}_{4}$ samples with different levels of conjugation and density of defects that exhibit distinct electrochemical and photoelectrochemical properties. The simplest synthesis, guaranteeing good results despite its low yield $(\sim 3 \%)$, is the pyrolysis of urea/thiourea, which could be carried out at several temperatures (from 450 to $600{ }^{\circ} \mathrm{C}$ ) in a conventional oven system in a non-inert atmosphere. ${ }^{17}$

The high versatility of $\mathrm{g}-\mathrm{C}_{3} \mathrm{~N}_{4}$ is mainly due to its conjugated structure with $\mathrm{sp}^{2}$ bonds between $\mathrm{C}$ and $\mathrm{N}$ atoms - like that of conducting polymers - which enables the easy modulation of its properties and 2D structural nature. While these nanostructured materials are stable under harsh conditions, being thermally (up to $600{ }^{\circ} \mathrm{C}$ in air) and chemically (under basic and acidic media) stable - unfortunately, carbon nitride shows poor solubility in most organic solvents, which hinders its processability. ${ }^{\mathbf{1 6}}$ However, this material can be easily exfoliated forming stable dispersion and nanostructures with interesting properties compared to the bulk material; such as formation of very stable dispersions, higher specific surface area, and altered surface electronic structure by the formation of polar surface docking sites. ${ }^{\mathbf{1 8 - 2 0}}$ In addition, most of the exfoliation procedures still use highly acid solutions (e.g. concentrated sulphuric acid or hydrochloric acid) to obtain the delaminated material. Hence, it is recommended to replace these conventional and non-environmentally friendly procedures by procedures that employ green solvents by applying mechanical forces, for example, water-alcohol mixtures applied to sonication processes. It is important to mention that, due to the formation of quite stable suspensions obtained by the exfoliation in water-alcohol mixtures, it becomes possible to perform the deposition of $\mathrm{C}_{3} \mathrm{~N}_{4}$ directly from the exfoliation solution on conductive substrates, increasing the range of applications of this material. Considering the exposed, graphitic carbon nitride $\left(\mathrm{g}-\mathrm{C}_{3} \mathrm{~N}_{4}\right)$ is a potential and promising graphene-like material to replace the GO or rGO in the development of supercapacitors.

Likewise, the use of carbon nitride as a supercapacitor material has already been reported in the literature, although the properties of pristine material have not been thoroughly studied. As shown earlier, synthetic routes for the preparation of $\mathrm{g}-\mathrm{C}_{3} \mathrm{~N}_{4}$ are very important to the definition of its properties; in this way, some papers were chosen to this study, in which the pyrolysis of urea/thiourea were the most widely used. Therefore, Guan et al. ${ }^{21}$ studied the morphology influence on the supercapacitance of $\mathrm{NiCo}_{2} \mathrm{O}_{4}$ nanostructures anchored on $\mathrm{C}_{3} \mathrm{~N}_{4}$ sheets. The $\mathrm{C}_{3} \mathrm{~N}_{4}$ was obtained via thiourea pyrolysis for $3 \mathrm{~h}$ at $550{ }^{\circ} \mathrm{C}$ and the composites were obtained via a hydrothermal method using nickel and cobalt chlorides as precursors. The authors verified that nanoneedles have $69 \mathrm{~F} \mathrm{~g}^{-1}$ at $2 \mathrm{~A} \mathrm{~g}^{-1}$ as capacitance and a retention rate of $101 \%$ after one thousand cycles. On the other hand, with the same cycling number, the nanosheets structures exhibited $253 \mathrm{~F} \mathrm{~g}^{-1}$ at $2 \mathrm{~A} \mathrm{~g}^{-1}$, however with a retention of only about $64 \%$. Another $\mathrm{Ni}-\mathrm{Co} / \mathrm{C}_{3} \mathrm{~N}_{4}$ composite was studied by Li et al., ${ }^{22}$ in which, a highly porous carbon nitride was produced using sublimated sulphur in the thiourea pyrolysis and then, the composite was obtained in autoclave system after $12 \mathrm{~h}$. This material exhibited optimum retention, maintaining $98 \%$ of its value of $206 \mathrm{~F} \mathrm{~g}^{-1}$ capacitance at $1 \mathrm{~A} \mathrm{~g}^{-1}$ after 1500 cycles.

Moreover, Shan et al. ${ }^{23}$ studied composites of $\mathrm{MnO}_{2}$ on $\mathrm{C}_{3} \mathrm{~N}_{4}$ pure and $\mathrm{C}_{3} \mathrm{~N}_{4}$ doped with $\mathrm{Na}$ or $\mathrm{K}$ single atoms. The synthesis was also carried out using thiourea and the doping was performed by adding the $\mathrm{KBr}$ and $\mathrm{NaBr}$ salts together with the thiourea to pyrolysis. The authors found that the non-doped composite showed $96 \mathrm{~F} \mathrm{~g}^{-1}$ of capacitance while the $\mathrm{K}$ and Na-doped showed values of 374 and $295 \mathrm{~F} \mathrm{~g}^{-1}$, respectively, at $0.2 \mathrm{~A} \mathrm{~g}^{-1}$. The lifetime of the materials was calculated after 1000 cycles at $1 \mathrm{~A} \mathrm{~g}^{-1}$, and retentions were $59.1 \%$ for the non-doped, $95.2 \%$ for the K-doped and $93.7 \%$ for the Na-doped material.

An interesting work using melamine as precursor was described by Tahir et al., ${ }^{24}$ in which the authors synthesized tubular structures of $\mathrm{C}_{3} \mathrm{~N}_{4}$. The nanostructure was obtained treating a melamine and ethylene glycol solution with $\mathrm{HNO}_{3}$ before annealing it at $450{ }^{\circ} \mathrm{C}$. A mixture of the obtained material and activated carbon was assembled on nickel foam and then electrochemically tested. The authors found a capacitance value of $233 \mathrm{~F} \mathrm{~g}^{-1}$ and $204 \mathrm{~F} \mathrm{~g}^{-1}$ for $0.2 \mathrm{~A} \mathrm{~g}^{-1}$ and $0.5 \mathrm{~A} \mathrm{~g}^{-1}$ respectively. The performance of capacitance retention after 1000 charge and discharge cycles was $90.9 \%$ and $89.2 \%$ for $0.2 \mathrm{~A} \mathrm{~g}^{-1}$ and $0.5 \mathrm{~A} \mathrm{~g}^{-1}$ respectively. Meanwhile, such results were compared with $\mathrm{C}_{3} \mathrm{~N}_{4}$ bulk samples prepared under similar conditions, which showed worse performance.

On the other hand, pure carbon nitride has been also studied by Tahir et al. ${ }^{25}$ - for this study the carbon nitride was produced from an ethanolic solution of melamine at $550{ }^{\circ} \mathrm{C}$ as graphitic carbon nitride nanofibers (GCNNF). This GCNNF showed a specific capacitance of $263.75 \mathrm{~F} \mathrm{~g}^{-1}$ at $1 \mathrm{~A} \mathrm{~g}^{-1}$ with a retention rate of $93.2 \%$ after 2000 charge/discharge cycles. With respect to this distinct citation regarding the properties of pure carbon nitride as supercapacitor there is a lack of important information about its durability to a greater number of charge and 
discharge cycles and their performance during them. In addition, the synthetic protocol is time consuming, needs higher temperature, and frequently needs a $\mathrm{N}_{2}$ or $\mathrm{Ar}$ atmosphere. It is also important to point out that most of the reported studies are performed in strongly basic aqueous medium and this route might generate waste from the washing steps $\left(\mathrm{OH}^{-}\right.$concentration higher than $1.0 \mathrm{~mol} \mathrm{~L}^{-1}$ ).

Considering these aspects, the present work aimed to evaluate the properties of pristine $\mathrm{C}_{3} \mathrm{~N}_{4}$ obtained by the pyrolysis of urea and subsequently exfoliated using an eco-friendly approach. The exfoliated carbon nitride was used as an active layer in metal-free supercapacitors with high cyclability and fully characterized using the physical techniques XRD, FTIR, SEM, EDX, TGA, DSC and $\mathrm{N}_{2}$ sorption in addition to the electrochemical techniques, cyclic voltammetry, charge/discharge curves and electrochemical impedance spectroscopy.

\section{Experimental}

\subsection{Reactants and materials}

All the chemicals used in this work were analytical grade and were used as received without further purification. Lithium perchlorate $\left(\mathrm{LiClO}_{4}\right)$ and acetonitrile (ACN) were purchased from Sigma-Aldrich (USA) and isopropanol and urea were purchased from Synth (Brazil). The ultrapure water was purified by an Milli-Q (Millipore) system.

\subsection{Carbon nitride synthesis}

The $\mathrm{g}-\mathrm{C}_{3} \mathrm{~N}_{4}$ was synthesized following the urea pyrolysis route. ${ }^{17}$ The urea was triturated, and then the powder was placed in a wide and deep refractory bowl. The sample was heated at a rate of $10{ }^{\circ} \mathrm{C} \mathrm{min}^{-1}$ in air atmosphere, the pyrolysis occurred at $500{ }^{\circ} \mathrm{C}$ for $2 \mathrm{~h}$ and then the sample was cooled down to room temperature. As a result, a yellowish fine powder was obtained. To prepare the electrodes $10 \mathrm{mg}$ of carbon nitride was dispersed in $5 \mathrm{~mL}$ of a mixture of water/isopropanol $(2: 1)$ in an ultrasonic bath for $3 \mathrm{~h}$, to exfoliate the $\mathrm{C}_{3} \mathrm{~N}_{4} \cdot{ }^{19}$ Then, $60 \mu \mathrm{L}$ of the dispersion was dropped on $1.0 \mathrm{~cm}^{2}$ delimited area of an FTO (fluoride doped tin oxide) substrate and then dried at $60{ }^{\circ} \mathrm{C}$ for $2 \mathrm{~h}$. The measurements of the substrate masses were accomplished before and after the deposition process to estimate the mass of the deposited film. Thus, the average mass of $0.49 \pm 0.02 \mathrm{mg}$ of deposited $\mathrm{C}_{3} \mathrm{~N}_{4}$, and the measured masses were used to calculate the normalized properties of the material.

\subsection{Electrochemical characterizations}

The electrochemical measurements were performed using a PGSTAT 302 Autolab electrochemical system with FRA2.0 module monitored with NOVA 1.11 software. The measurements were carried out in $\mathrm{LiClO}_{4} 1.0 \mathrm{~mol} \mathrm{~L}{ }^{-1}$ acetonitrile solution using a conventional electrochemical cell purged with $\mathrm{N}_{2}$ during the processes. A pseudo reference electrode was used (Ag wire). The cyclic voltammetry (CV) was performed between 0.2 and $0.8 \mathrm{~V}$ at several scans rate (from 20 to $120 \mathrm{mV} \mathrm{s}^{-1}$ ). The galvanostatic charge/discharge $(\mathrm{CnD})$ curves were performed in the same potential window applying different currents (from 0.2 to $9.0 \mathrm{~A} \mathrm{~g}^{-1}$ ). The aging of the material was studied by cycling the films using the $\mathrm{CnD}$ measurements at $3.0 \mathrm{~A} \mathrm{~g}^{-1}$. The electrochemical impedance spectroscopy (EIS) data was obtained at open circuit potential (OCP) between $10 \mathrm{kHz}$ and $100 \mathrm{mHz}$ with perturbation of $10 \mathrm{mV}_{\mathrm{rms}}$; the data was fitted using the transmission line model. Both, CV and EIS measurements were taken before each $250 \mathrm{CnD}$ cycles.

\subsection{Physical characterizations}

The electrode morphology characterization and elementary analysis were performed by Scanning Electron Microscopy (SEM) and EDX (Energy Dispersive X-ray spectrum) in a FEI Inspect microscope model F50 equipped with EDX detector. The crystalline structure was characterized using X-ray diffraction technique in an XRD-6000 Shimadzu X-Ray diffractometer in step scan mode $\left(2^{\circ} \mathrm{min}^{-1}\right)$ with $\mathrm{CuK} \alpha 1.5406 \AA$. The chemical bonds structure was characterized in both Fourier-transformed infrared by diffuse reflectance method (FTIR-DRIFTS) using a Bruker EQUINOX 55 infrared spectrometer and Raman spectra using a Bruker RFS 100/S spectrometer using as excitation source a YAG:Nd laser (1064 nm). Additionally, aiming to investigate the purity of the obtained $\mathrm{C}_{3} \mathrm{~N}_{4}$, Differential Scanning Calorimetry (DSC) and thermogravimetric analysis (TGA) were performed in TG/DSC analyser model STA 449 F3 Jupiter (Netzsch) equipment; a heating rate of $10{ }^{\circ} \mathrm{C} \mathrm{min}^{-1}$ in an open alumina crucible in an atmosphere of synthetic air $\left(80 \% \mathrm{~N}_{2}\right.$ and $20 \% \mathrm{O}_{2}$ ) was used. Nitrogen adsorption/desorption isotherms were acquired using a Micromeritics ASAP 2010 instrument; the Brunauer-Emmett-Teller (BET) method ${ }^{26}$ was applied to obtain the specific surface area. Finally, the exfoliation effect over the $\mathrm{C}_{3} \mathrm{~N}_{4}$ electronic structure was evaluated using Diffuse Reflectance to build a Kubelka-Munk plot, was used a Cary 5G spectrometer to acquire the reflectance diffuse data.

\section{Results and discussion}

After obtaining the $\mathrm{g}-\mathrm{C}_{3} \mathrm{~N}_{4}$ and its subsequently exfoliation, the characterizations were made to ensure that the material prepared was $\mathrm{C}_{3} \mathrm{~N}_{4}$ free of urea impurities. In this way, Fig. 1a and $b$ show the X-ray diffraction and the FTIR spectra of both bulk and exfoliated material, to demonstrate that the material was not altered by the exfoliation process, in which both XRD pattern and infrared spectra are consistent with those reported in the literature. ${ }^{1627-29}$ In the XRD diffractogram (Fig. 1a), as expected, two diffraction peaks located at $13.1^{\circ}$ and $27.5^{\circ}$ confirm the carbon nitride crystalline structure. ${ }^{27,28}$ FTIR spectra (Fig. 1b) exhibited no change between exfoliated and bulk material. Both spectra show the fingerprint for the $\mathrm{C}_{3} \mathrm{~N}_{4}$, bands assigned to the $\mathrm{N}-\mathrm{H}$ stretching at $3190 \mathrm{~cm}^{-1}$, bands from 1570 to $1620 \mathrm{~cm}^{-1}$ and 1250 to $1430 \mathrm{~cm}^{-1}$ assigned to the $\mathrm{C}-\mathrm{N}$ and $\mathrm{C}=\mathrm{N}$ stretching, respectively; and one intense and narrow band at $810 \mathrm{~cm}^{-1}$ assigned to the $\mathrm{C}-\mathrm{N}$ angular deformation in the heterocyclic structure. ${ }^{29}$ The difference in the intensity and the separation in the broadband from 1110 to $1780 \mathrm{~cm}^{-1}$ is attributed to the high conjugation degree of the $\mathrm{C}_{3} \mathrm{~N}_{4}$ structure. Furthermore, the Urea XRD and FTIR spectrum is provided in 

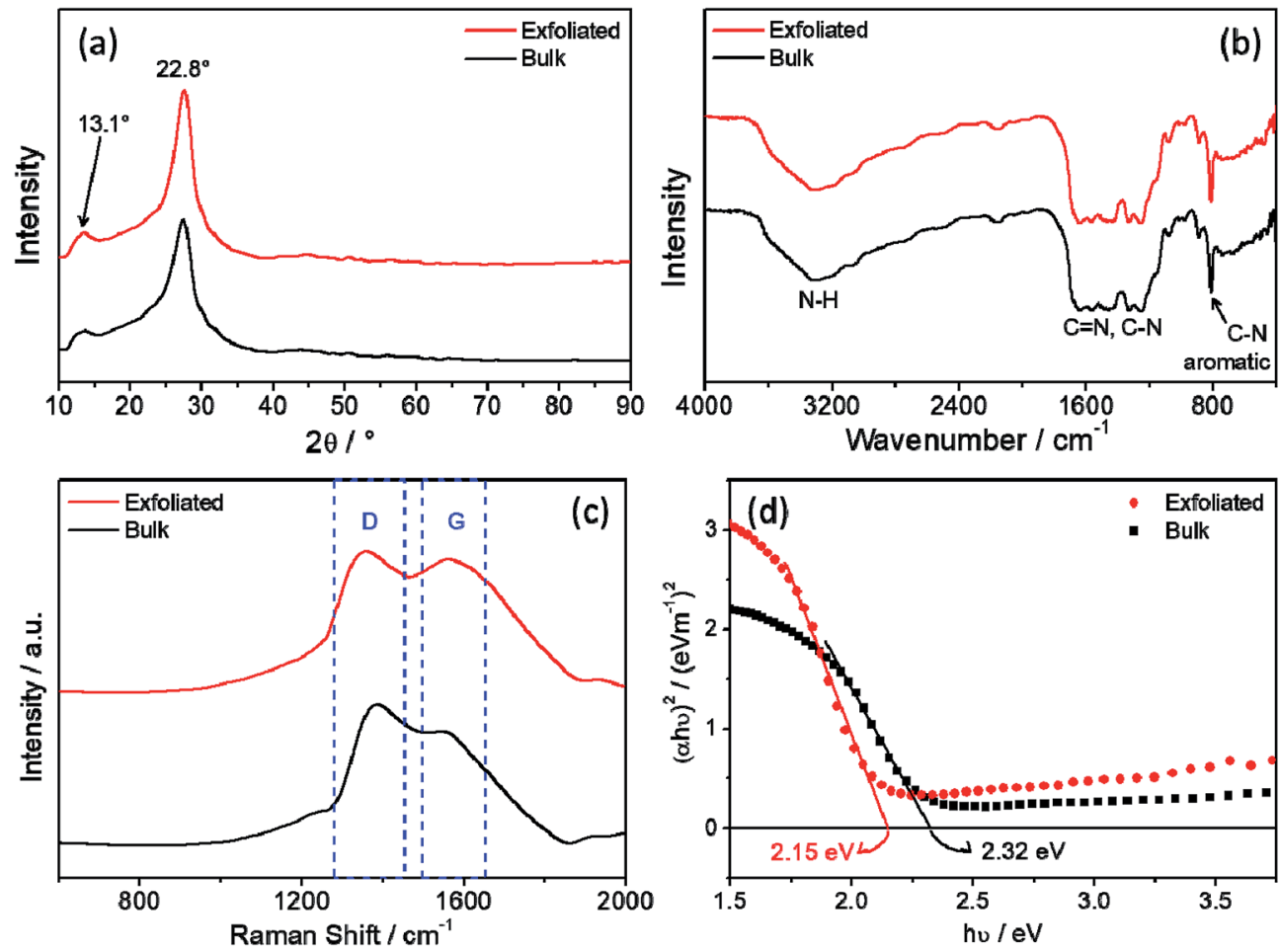

Fig. 1 (a) X-Ray diffraction (XRD) pattern, (b) Fourier-transformed infrared spectra (FTIR), (c) Raman spectra and (d) Kubelka-Munk plot of bulk and exfoliated $\mathrm{C}_{3} \mathrm{~N}_{4}$.

ESI, Section S.I. $1, \dagger$ in which comparing with results of the carbon nitride, it is not possible to observe the presence of peaks related to urea as contamination in both XRD and FTIR spectra. In addition, thermal analysis suggested a complete conversion of the urea precursor into carbon nitride material, as shown in Fig. S2. $\dagger$

In the Raman spectra (Fig. 1c) is possible to see for both samples the $\mathrm{D}$ and $\mathrm{G}$ bands, as in graphene the $\mathrm{D}$ and $\mathrm{G}$ bands is related to the edge and basal planes respectively. So, in the exfoliated sample it is possible to observe a broadening of the peaks, this could be related to the loss of organization that existed when the $\mathrm{C}_{3} \mathrm{~N}_{4}$ sheets were stacked, in addition the relative intensity between these two bands also underwent a change, as expected the $\mathrm{G}$ band became more intense due to the release of the basal planes. ${ }^{30,31}$ Fig. $1 \mathrm{~d}$ show the KubelkaMunk plot and the calculated bandgap energy for both samples, it was described in the literature that the exfoliation process leads to a slightly decrease of the band gap energy $\left(E_{\mathrm{g}}\right)^{18,19,32}$ Thus, although the DRX profile and the FTIR spectra did not show significant change, the Raman spectra and $E_{\mathrm{g}}$ values evidenced the change suffered by carbon nitride after mechanical exfoliation.

Fig. 2 shows the morphology of the carbon nitride flakes deposited on FTO, in which the exfoliated sheets are very thin and transparent (inset image). Besides, the $\mathrm{C}_{3} \mathrm{~N}_{4}$ presented a rough surface with the aspect of a crumpled paper-sheet, suggesting a high porosity in this material. Keeping in mind that the pseudocapacitance from the double-layer depends on the electrochemical active area and is proportional to the surface area, these characteristics are very important to

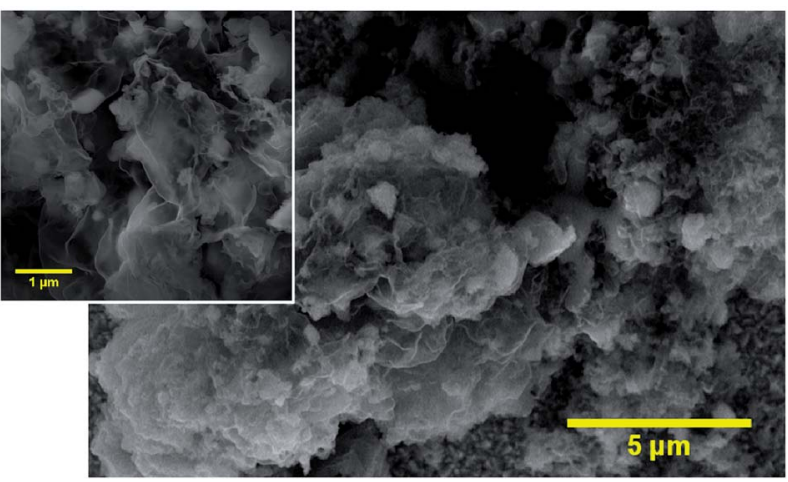

Fig. 2 Deposited $\mathrm{C}_{3} \mathrm{~N}_{4}$ film on FTO substrate Scanning Electron Microscopy (SEM) image in $3 \mathrm{k} \times$ and $10 \mathrm{k} \times$ (inset) magnification.

achieving high specific capacitance. From the $\mathrm{N}_{2}$ adsorption curve (using BET model) it was found that the material obtained in this work has $38.5 \mathrm{~m}^{2} \mathrm{~g}^{-1}$, compatible with the results found in the literature.$^{16}$ Complete adsorption isotherms are provided in the ESI, Section S.I. 2. $\dagger$

The capacitor properties were characterized using cyclic voltammetry (Fig. 3a) and charge/discharge curves (Fig. 3b), varying sweep velocity and specific current applied, respectively. The charge/discharge measurements were performed between the potential cut-off limits of 0.2 and $0.8 \mathrm{~V}$, and the same potential window was used for the cyclic voltammetry scan. The specific capacitance was calculated from the slope of the linear region of the discharge curves and from the voltammetry, it was calculated using the oxidation charge, as proposed by Ramya 

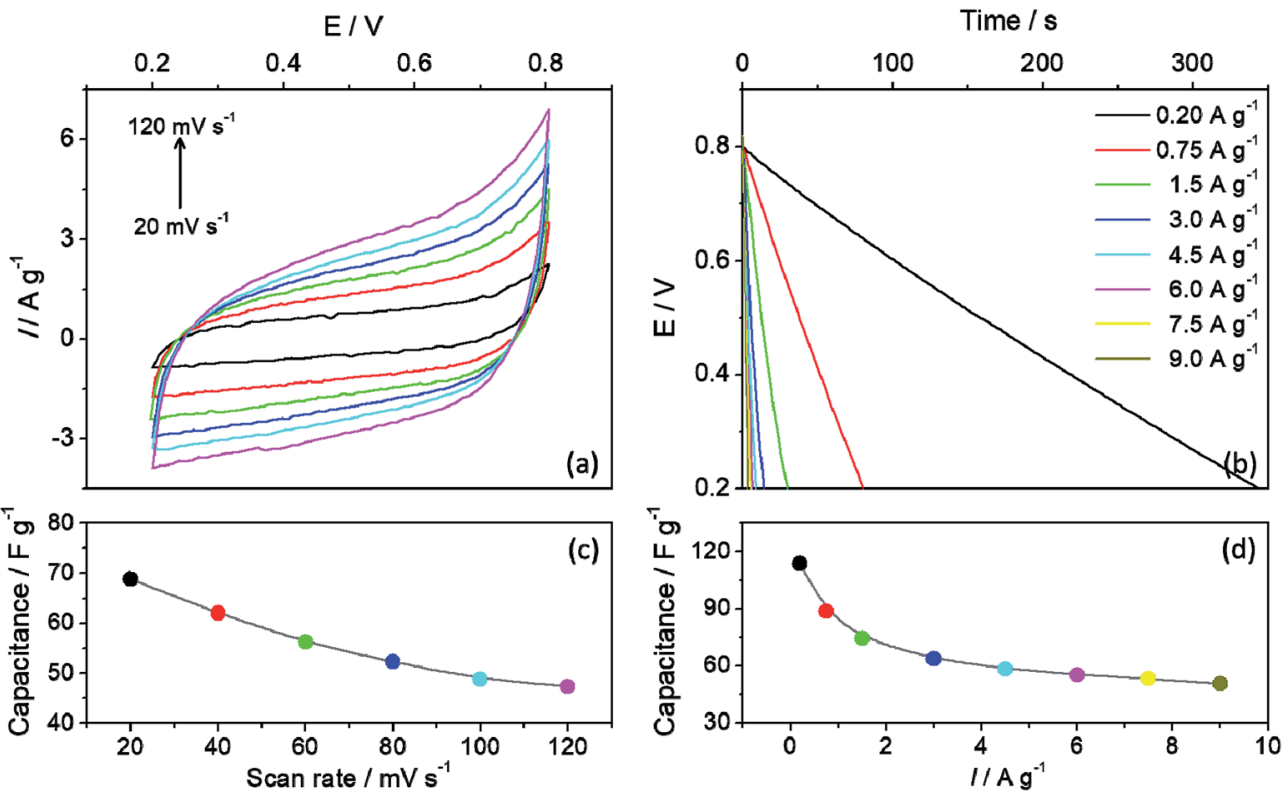

Fig. 3 (a) Cyclic voltammetries in several scan rates and (b) discharge curves in several specific currents and specific capacitance as a function of (c) scan rate and (d) specific current. Both performed in ACN/0.1 mol L $\mathrm{LiClO}_{4}$.

et al. ${ }^{33}$ Both specific capacitance as a function of the scan rate (Fig. 3c) and as a function of the specific current (Fig. 3d) decrease with the increase of the charge and discharge rate, which could mean that these processes are diffusion controlled, as expected for a redox supercapacitor. The specific capacitance retention calculated for the $\mathrm{CV}$ scan rate function was $68.9 \%$ and $54.4 \%$ for the $\mathrm{CnD}$ specific current function. Besides, the cyclic voltammetry does not exhibit any characteristic peak for oxidation/reduction processes in the potential window studied. In addition, the material also does not exhibit the standard rectangular shape of a capacitive behaviour, which could be also seen in the triangular-shape in the $\mathrm{CnD}$ curves. Additionally, there is a certain slope in the voltammogram, which suggests that the film has considerable resistivity. Taking into account
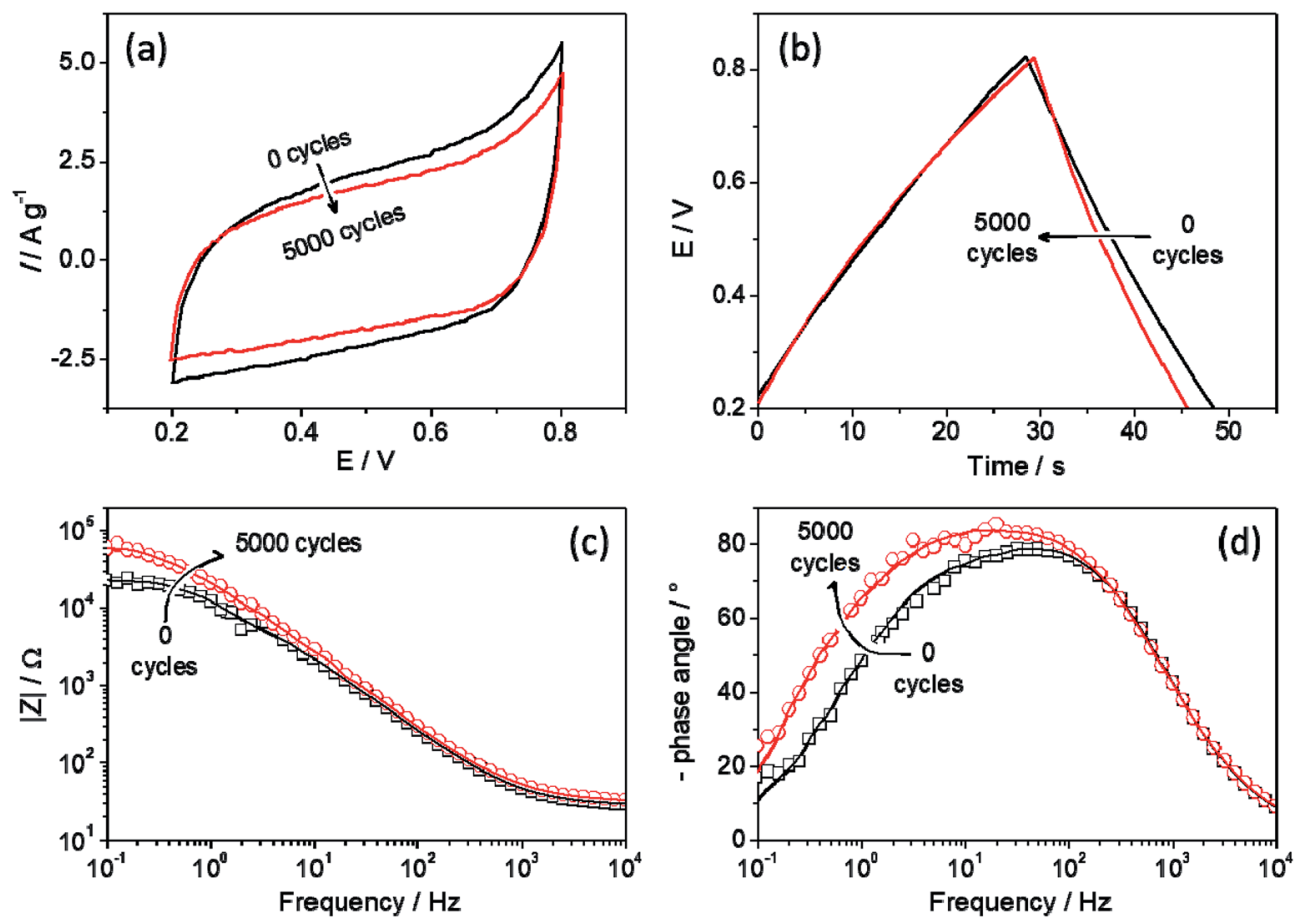

Fig. 4 (a) cyclic voltammetries, (b) charge/discharge curves at $3.0 \mathrm{~A} \mathrm{~g}^{-1}$, (c) Bode modulus plot and (d) Bode phase plot before and after $5 \mathrm{k}$ CnD cycles. 


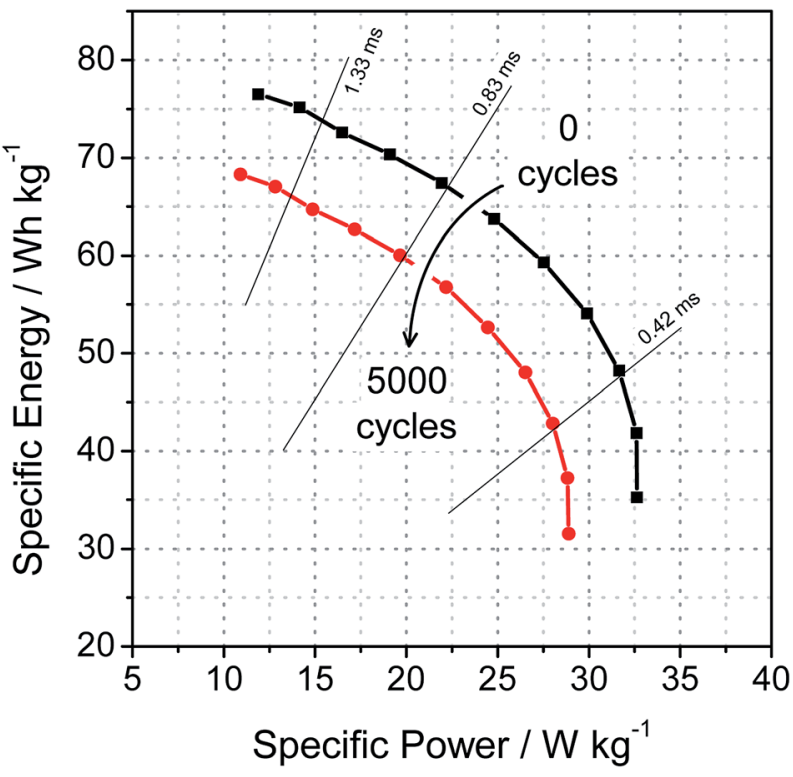

Fig. 5 Ragone chart obtained from impedance data before and after cycling 5000 times.

the $\mathrm{C}_{3} \mathrm{~N}_{4}$ lamellar and porous structure, this resistivity and shape deviation is associated to a pseudo capacitance due to the redox transformations. ${ }^{34,35}$

To evaluate the durability of the $\mathrm{C}_{3} \mathrm{~N}_{4}$ film, the electrode was cycled 5000 times, in which at regular intervals, cyclic voltammetry and impedance spectroscopy data were collected, to obtain more insights regarding the aging of the film. Fig. 3 shows the changes in the $\mathrm{CV}, \mathrm{CnD}$ curves and EIS data before and after 5000 cycles. The shape of CV profile remained the same even after the $5 \mathrm{k}$ cycles, although a small decrease in the current values (Fig. 4a) was observed and the same behaviour was noted in the $\mathrm{CnD}$ curves (Fig. 4a). From the first $\mathrm{CnD}$ cycle, the discharge process occurs slightly faster (from $20.6 \mathrm{~s}$ to 16.5 s), which leads to a small decrease in the capacitance value. Nevertheless, it is interesting to note that the charging time increased with the aging, leading to a lost in the coulombic efficiency.

Fig. 4c and d show important changes in the impedance data. First, there is no significant change in the system impedance at high frequency, suggesting that the inherent electrode processes are not modified due to the charge and discharge cycles. Otherwise, at low frequency region there is an increase in the impedance, suggesting that slower processes, such as ion intercalation, are slower after cycling. With respect to the system at constant time, in Fig. 3d it is possible to see a displacement to low frequency (from $37.1 \mathrm{~Hz}$ to $15.8 \mathrm{~Hz}$ ), which means that the process to which it associates takes a longer time to occur, $36.4 \mathrm{~ms}$ more. This constant time could be associated with the ion intercalation process due to the charge and discharging scan that takes longer to happen after the $5 \mathrm{k}$ cycles.

From the Ragone chart, it is possible to find important values to measure the performance of a supercapacitor, namely, maximum specific energy and maximum specific power. Each point in the curve is given as the ratio between the energy and the power densities, characterizing the rate that a given amount of energy is supplied as a function of power. Straight diagonals that cross the isocurves indicate the operating time of the capacitor and its respective power and energy amount. These curves are very interesting because they provide a clear idea of the possible application of the studied device, since different uses require different combinations of power and energy.

Such curves can be estimated from the impedance data by applying a simple relation between the admittance and the disturbance that was applied in the system during data acquisition. Thus, as described by Kurzweil, ${ }^{36}$ the eqn (1) and the eqn (2) are used to calculate the specific energy and specific power, respectively,

$$
\begin{gathered}
\text { Specific energy : } Q=(-U)^{2}\left(\frac{-Z^{\prime \prime}}{|Z|^{2}}\right) \times \frac{1}{m} \\
\text { Specific power : } P=U^{2}\left(\frac{Z^{\prime}}{|Z|^{2}}\right) \times \frac{1}{m}
\end{gathered}
$$

where, $U$ is the rms potential; $Z$ is the impedance modulus; $Z^{\prime}$ is the real part of the impedance; $-Z^{\prime \prime}$ is the imaginary part of the impedance and $m$, the mass of active layer. Although, the Ragone chart is used for two-electrode devices to measure it performance, is described in some papers that it is possible to obtain important information from the three-electrodes configuration..$^{37-41}$ Therefore, with this information, it is possible to obtain some important information about the system and then, obtain an idea of the final device performance.

In the light of the aforementioned, Fig. 5 shows the isocurves for the $\mathrm{C}_{3} \mathrm{~N}_{4}$ before and after the 5000 charge and discharge cycles, in which both curves are expected for supercapacitors, although they show relatively low values of specific power compared to other types of devices. ${ }^{1}$ In the first applications, the material can deliver a maximum specific energy of $76.5 \mathrm{~W} \mathrm{~h} \mathrm{~kg}^{-1}$ with a power of $11.9 \mathrm{~W} \mathrm{~kg}^{-1}$; but for subsequent applications it can deliver $35.3 \mathrm{~W} \mathrm{~h} \mathrm{~kg}^{-1}$ with a maximum power of $32.6 \mathrm{~W} \mathrm{~kg}^{-1}$. Also, after cycling, the maximum specific energy that can be used decreases to $68.3 \mathrm{~W} \mathrm{~h} \mathrm{~kg}^{-1}$ at a power of $10.9 \mathrm{~W}$ $\mathrm{kg}^{-1}$ and supplying $31.5 \mathrm{~W} \mathrm{~h} \mathrm{~kg}^{-1}$ with a maximum power of $28.9 \mathrm{~W} \mathrm{~kg}^{-1}$. These results demonstrate that this device can deliver its maximum of energy with 3 times less power than maximum operating power or likewise, deliver half of its maximum energy with its maximum operating power. Furthermore, in order to exemplify its properties, a capacitor made of $42.0 \mathrm{~g}$ of this electroactive material would be required to start a Toyota Brushless ACPM motor (Toyota Prius 2004). . $2,43^{4}$

In terms of specific energy, these values are similar to other reported $\mathrm{C}_{3} \mathrm{~N}_{4}$ composites supercapacitors. ${ }^{21,44-46}$ It is important to mention that such works refer to complex materials and composites that have some metal, whereas the present work refers to a single material that is metal-free, which is a huge advantage in the current concerns about the environment. On the other hand, the specific power values are low when compared to the similar materials, such as graphene-based 


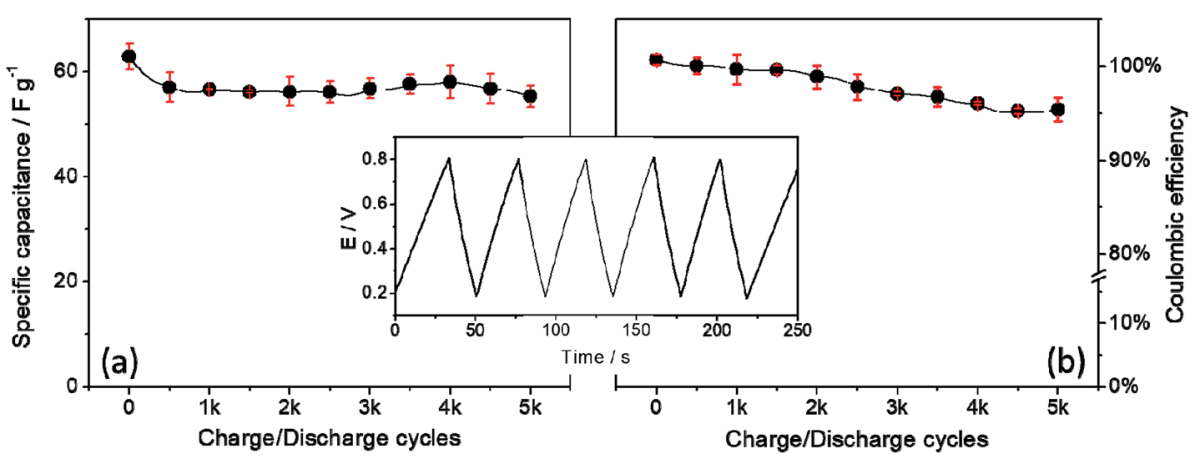

Fig. 6 (a) specific capacitance and coulombic efficiency in function of charge/discharge cycles at $3.0 \mathrm{~A} \mathrm{~g}^{-1}$ (the inset contains the first charge/ discharge cycles).

materials ${ }^{47}$ and the $\mathrm{CoS}_{2} / \mathrm{g}-\mathrm{C}_{3} \mathrm{~N}_{4}$ composites studied by Jiang et $a l .{ }^{48}$ However, it is important to mention that the delivery time at the maximum and minimum operating powers lies between $2 \mathrm{~ms}$ and $0.2 \mathrm{~ms}$ respectively, being quite reasonable for an organic and metal-free supercapacitor. Since the power information from that Ragone chart was obtained from the real part of the impedance data, this low specific power to the high charge-transfer resistance found for the electrode sample (2.29 $\mathrm{k} \Omega$ ), is assigned to the ion intercalation in the lamellar matrix of the carbon nitride. ${ }^{16,18}$

Since the durability of a capacitor is as important as its stability, it was similarly evaluated the properties of the material during the CnD cycles. Thus, Fig. 6 shows the specific capacitance and coulombic efficiency over the $5 \mathrm{k}$ cycles. Initially, the capacitance value is $62.8 \mathrm{~F} \mathrm{~g}^{-1}$, followed by a significant drop, after this initial drop, the capacitance remains constant during the cycles, showing a retention rate of $89.2 \%$ of the capacitance value (Fig. 6a), which is a quite impressive value for a pure material. As seen earlier, initially the loading time was slightly lower than the discharge time, reversing such a relationship with the successive $\mathrm{CnD}$ cycles. In such way, the coulombic efficiency at the beginning of the aging study was of $101.6 \%$ before 5000 cycles but this value drops to $95.4 \%$, suggesting an initial change in the film structure and then being stabilized.
The electrochemical characterizations allowed evaluating the applicability of pure $\mathrm{C}_{3} \mathrm{~N}_{4}$ as an active layer in electrochemical capacitors. In addition, it is important to note that the material was obtained in a simple way and using few operations, which were required to it deposition over the electrode surface. The capacitance value and the high cyclability life-time observed in this study are compatible with the results already reported in the literature for composites with longer timeconsuming preparations. In this context, these results suggest that pure $\mathrm{C}_{3} \mathrm{~N}_{4}$ is a quite promising organic supercapacitor material for energy storage purposes, being easily prepared, cheap, metal-free, and environmentally friendly.

Considering the above aspects, the synthesis of some composites causes the $\mathrm{C}_{3} \mathrm{~N}_{4}$ sheets flattening; thus, the addition of this second material does not compensate the properties lost because of $\mathrm{C}_{3} \mathrm{~N}_{4}$ sheets structural change, leading to a worsening of its properties. Likewise, some oxides addition could lead to the pore blockage, which in same way leads to a decrease in properties. Thus, it is important to note that this bare material showed a superior performance than other composites using g- $\mathrm{C}_{3} \mathrm{~N}_{4}$ as base material, as summarized in Table 1.

Such results reinforce the need for an appropriate study of materials in their pure form prior to evaluating such composites, since these composites might represent a cost

Table 1 Comparison of several $\mathrm{C}_{3} \mathrm{~N}_{4}$-based materials and its performance as supercapacitor material

\begin{tabular}{|c|c|c|c|c|}
\hline Material & Capacitance/F $\mathrm{g}^{-1}$ & Retention/\% & Cycles number & Ref. \\
\hline $\mathrm{NiCo}_{2} \mathrm{O}_{4}$ nanoneedles $/ \mathrm{C}_{3} \mathrm{~N}_{4}$ & 69 & 101 & 1000 & 21 \\
\hline $\mathrm{NiCo}_{2} \mathrm{O}_{4}$ nanosheets $/ \mathrm{C}_{3} \mathrm{~N}_{4}$ & 253 & 64.0 & 1000 & 21 \\
\hline $\mathrm{MnO}_{2} /$ non-doped $\mathrm{C}_{3} \mathrm{~N}_{4}$ & 96 & 59.1 & 1000 & 23 \\
\hline $\mathrm{MnO}_{2} / \mathrm{Na}$-doped $\mathrm{C}_{3} \mathrm{~N}_{4}$ & 374 & 95.2 & 1000 & 23 \\
\hline $\mathrm{MnO}_{2} / \mathrm{K}$-doped $\mathrm{C}_{3} \mathrm{~N}_{4}$ & 295 & 93.7 & 1000 & 23 \\
\hline Flower-like PANI/g- $\mathrm{C}_{3} \mathrm{~N}_{4}$ & 584 & 81.9 & 1000 & 49 \\
\hline $\mathrm{PEDOT} / \mathrm{g}-\mathrm{C}_{3} \mathrm{~N}_{4}$ in $\mathrm{H}_{2} \mathrm{SO}_{4}$ & 137 & 89.0 & 1000 & 50 \\
\hline $\mathrm{PEDOT} / \mathrm{g}-\mathrm{C}_{3} \mathrm{~N}_{4}$ in $\mathrm{Na}_{2} \mathrm{SO}_{4}$ & 200 & 96.5 & 1000 & 50 \\
\hline $\mathrm{MnO}_{2}$ nanorods $/ \mathrm{g}-\mathrm{C}_{3} \mathrm{~N}_{4}$ & 211 & 99.9 & 1000 & 51 \\
\hline Exfoliated bare $\mathrm{C}_{3} \mathrm{~N}_{4}$ & 113.7 & 89.3 & 5000 & This work \\
\hline
\end{tabular}


increasing in the development of new materials that may not be justified once there is a small improvement of their properties.

\section{Conclusions}

The properties of an electrode made only of exfoliated g- $\mathrm{C}_{3} \mathrm{~N}_{4}$, which was easily synthesized via a simple method, from readily available material were evaluated. The material, tested in organic medium with $0.1 \mathrm{M} \mathrm{LiClO}_{4}$ as electrolyte into the potential window of 0.2 to $0.8 \mathrm{~V}$, showed a capacitance of 113.7 $\mathrm{F} \mathrm{g}^{-1}$ at $0.20 \mathrm{~F} \mathrm{~g}^{-1}$ with impressive durability for a pristine material with a retention rate of $89.3 \%$ after 5000 charge and discharge cycles at $3.0 \mathrm{~A} \mathrm{~g}^{-1}$. Moreover, the material showed a large amount of specific energy $\left(76.5 \mathrm{~W} \mathrm{~h} \mathrm{~kg}^{-1}\right)$ at an operating power of $11.9 \mathrm{~W} \mathrm{~kg}^{-1}$, which demonstrated a drop of only $89.3 \%$ due to electrochemical aging. Furthermore, it was noted that the performance of the pure carbon nitride was superior to other composites found in the literature. It is highlighted that these results are of great importance for understanding the inherent properties of carbon nitride to develop composites to increase their specific capacitance values while maintaining both their longer lifetime and their specific energy.

\section{Conflicts of interest}

There are no conflicts to declare.

\section{Acknowledgements}

The authors are grateful to the funding agencies that supported this research, FAPESP (2011/10897-2, 2013/07296-2 and 15/ 17141-1), FAPESP-GSK (2014/50249-8), CAPES and CNPq. R. Gonçalves and T. M. Lima are grateful for their PhD and postdoctoral fellowships, respectively (CNPq 166203/2014-9 and FAPESP 2017/06536-0). The authors also would like to thank for the readiness and the help with the thermal analysis measurements performed by MSc. Eng. Tiago dos Santos Junior of the Materials Engineering Microstructure Group (GEMM) of the Federal University of Sao Carlos.

\section{References}

$1 \mathrm{P}$. Simon and Y. Gogotsi, Materials for electrochemical capacitors, Nat. Mater., 2008, 7, 845-854.

2 J. Bisquert, Physical electrochemistry of nanostructured devices, Phys. Chem. Chem. Phys., 2008, 10, 49-72.

3 H. Gleiter, Nanostructured materials: basic concepts and microstructure, Acta Mater., 2000, 48, 1-29.

4 A. González, E. Goikolea, J. A. Barrena and R. Mysyk, Review on supercapacitors: technologies and materials, Renewable Sustainable Energy Rev., 2016, 58, 1189-1206.

5 B. E. Conway, in Electrochemical Supercapacitors, Springer, Boston, MA, US, 1999, pp. 221-257.

6 M. Irimia-Vladu, "Green" electronics: biodegradable and biocompatible materials and devices for sustainable future, Chem. Soc. Rev., 2014, 43, 588-610.
7 V. Singh, D. Joung, L. Zhai, S. Das, S. I. Khondaker and S. Seal, Graphene based materials: past, present and future, Prog. Mater. Sci., 2011, 56, 1178-1271.

8 H. Wang, H. S. Casalongue, Y. Liang and H. Dai, $\mathrm{Ni}(\mathrm{OH})_{2}$ Nanoplates Grown on Graphene as Advanced Electrochemical Pseudocapacitor Materials, J. Am. Chem. Soc., 2010, 132, 7472-7477.

9 J.-S. Lee, S.-I. Kim, J.-C. Yoon and J.-H. Jang, Chemical Vapor Deposition of Mesoporous Graphene Nanoballs for Supercapacitor, ACS Nano, 2013, 7, 6047-6055.

10 J. Wu, Q. Zhang, J. Wang, X. Huang and H. Bai, A selfassembly route to porous polyaniline/reduced graphene oxide composite materials with molecular-level uniformity for high-performance supercapacitors, Energy Environ. Sci., 2018, 11, 1280-1286.

11 W. Liu, M. Ulaganathan, I. Abdelwahab, X. Luo, Z. Chen, S. J. Rong Tan, X. Wang, Y. Liu, D. Geng, Y. Bao, J. Chen and K. P. Loh, Two-Dimensional Polymer Synthesized via Solid-State Polymerization for High-Performance Supercapacitors, ACS Nano, 2018, 12, 852-860.

12 L. Yu, L. Hu, B. Anasori, Y.-T. Liu, Q. Zhu, P. Zhang, Y. Gogotsi and B. Xu, MXene-Bonded Activated Carbon as a Flexible Electrode for High-Performance Supercapacitors, ACS Energy Lett., 2018, 3, 1597-1603.

13 K. Krishnamoorthy, P. Pazhamalai and S.-J. Kim, Twodimensional siloxene nanosheets: novel high-performance supercapacitor electrode materials, Energy Environ. Sci., 2018, 11, 1595-1602.

14 J. V. Liebing, About Some Nitrogen Compounds, Ann. Pharm., 1834, 10, 10.

15 P. H. Martínez, K. C. Hultzsch and F. Hampel, Base-catalysed asymmetric hydroamination/cyclisation of aminoalkenes utilising a dimeric chiral diamidobinaphthyl dilithium salt, Chem. Commun., 2006, 2221-2223.

16 W.-J. J. Ong, L.-L. L. Tan, Y. H. Ng, S.-T. T. Yong and S.-P. P. Chai, Graphitic Carbon Nitride $\left(\mathrm{g}-\mathrm{C}_{3} \mathrm{~N}_{4}\right)$-Based Photocatalysts for Artificial Photosynthesis and Environmental Remediation: Are We a Step Closer to Achieving Sustainability?, Chem. Rev., 2016, 116, 7159-7329.

17 Y. Zhang, J. Liu, G. Wu and W. Chen, Porous graphitic carbon nitride synthesized via direct polymerization of urea for efficient sunlight-driven photocatalytic hydrogen production, Nanoscale, 2012, 4, 5300.

18 H. Sun, X. Zhou, H. Zhang and W. Tu, An efficient exfoliation method to obtain graphitic carbon nitride nanosheets with superior visible-light photocatalytic activity, Int. J. Hydrogen Energy, 2017, 42, 7930-7937.

19 X. She, H. Xu, Y. Xu, J. Yan, J. Xia, L. Xu, Y. Song, Y. Jiang, Q. Zhang and H. Li, Exfoliated graphene-like carbon nitride in organic solvents: enhanced photocatalytic activity and highly selective and sensitive sensor for the detection of trace amounts of $\mathrm{Cu}^{2+}, J$. Mater. Chem. A, 2014, 2, 2563.

20 Z. Lin and X. Wang, Nanostructure Engineering and Doping of Conjugated Carbon Nitride Semiconductors for Hydrogen Photosynthesis, Angew. Chem., Int. Ed., 2013, 52, 1735-1738. 
21 B. Guan, Q. Y. Shan, H. Chen, D. Xue, K. Chen and Y. X. Zhang, Morphology Dependent Supercapacitance of Nanostructured $\mathrm{NiCo}_{2} \mathrm{O}_{4}$ on Graphitic Carbon Nitride, Electrochim. Acta, 2016, 200, 239-246.

22 Z. Li, L. Wu, L. Wang, A. Gu and Q. Zhou, Nickel cobalt sulfide nanosheets uniformly anchored on porous graphitic carbon nitride for supercapacitors with high cycling performance, Electrochim. Acta, 2017, 231, 617-625.

23 Q. Y. Shan, X. L. Guo, F. Dong and Y. X. Zhang, Single atom (K/Na) doped graphitic carbon nitride@ $\mathrm{MnO}_{2}$ as an efficient electrode Material for supercapacitor, Mater. Lett., 2017, 202, 103-106.

24 M. Tahir, C. Cao, F. K. Butt, F. Idrees, N. Mahmood, Z. Ali, I. Aslam, M. Tanveer, M. Rizwan and T. Mahmood, Tubular graphitic- $\mathrm{C}_{3} \mathrm{~N}_{4}$ : a prospective material for energy storage and green photocatalysis, J. Mater. Chem. A, 2013, $1,13949$.

25 M. Tahir, C. Cao, N. Mahmood, F. K. Butt, A. Mahmood, F. Idrees, S. Hussain, M. Tanveer, Z. Ali and I. Aslam, Multifunctional g- $\mathrm{C}_{3} \mathrm{~N}_{4}$ Nanofibers: A Template-Free Fabrication and Enhanced Optical, Electrochemical, and Photocatalyst Properties, ACS Appl. Mater. Interfaces, 2014, 6, 1258-1265.

26 S. Brunauer, P. H. Emmett and E. Teller, Adsorption of Gases in Multimolecular Layers, J. Am. Chem. Soc., 1938, 60, 309319.

27 J. Liu, T. Zhang, Z. Wang, G. Dawson and W. Chen, Simple pyrolysis of urea into graphitic carbon nitride with recyclable adsorption and photocatalytic activity, J. Mater. Chem., 2011, 21, 14398.

28 Y. Zheng, Z. Zhang and C. Li, A comparison of graphitic carbon nitrides synthesized from different precursors through pyrolysis, J. Photochem. Photobiol., A, 2017, 332, 32-44.

29 M. Kim, S. Hwang and J.-S. Yu, Novel ordered nanoporous graphitic $\mathrm{C}_{3} \mathrm{~N}_{4}$ as a support for $\mathrm{Pt}-\mathrm{Ru}$ anode catalyst in direct methanol fuel cell, J. Mater. Chem., 2007, 17, 16561659.

30 P. V. Zinin, L.-C. Ming, S. K. Sharma, V. N. Khabashesku, X. Liu, S. Hong, S. Endo and T. Acosta, Ultraviolet and near-infrared Raman spectroscopy of graphitic $\mathrm{C}_{3} \mathrm{~N}_{4}$ phase, Chem. Phys. Lett., 2009, 472, 69-73.

31 J. Jiang, L. Ou-yang, L. Zhu, A. Zheng, J. Zou, X. Yi and H. Tang, Dependence of electronic structure of $\mathrm{g}-\mathrm{C}_{3} \mathrm{~N}_{4}$ on the layer number of its nanosheets: A study by Raman spectroscopy coupled with first-principles calculations, Carbon, 2014, 80, 213-221.

32 S. Yang, Y. Gong, J. Zhang, L. Zhan, L. Ma, Z. Fang, R. Vajtai, X. Wang and P. M. Ajayan, Exfoliated graphitic carbon nitride nanosheets as efficient catalysts for hydrogen evolution under visible light, Adv. Mater., 2013, 25, 24522456.

33 R. Ramya, R. Sivasubramanian and M. V. Sangaranarayanan, Conducting polymers-based electrochemical supercapacitors-Progress and prospects, Electrochim. Acta, 2013, 101, 109-129.
$34 \mathrm{~L}$. Yu and G. Z. Chen, Redox electrode materials for supercapatteries, J. Power Sources, 2016, 326, 604-612.

35 B. E. Conway and W. G. Pell, Power limitations of supercapacitor operation associated with resistance and capacitance distribution in porous electrode devices, $J$. Power Sources, 2002, 105, 169-181.

36 P. Kurzweil, ac Impedance Spectroscopy - A Powerful Tool for the Characterization of Materials and Electrochemical Power Sources, 14th Int. Semin. double layer Capacit. hybrid energy storage devices, 2004, pp. 1-15.

37 D. Torregrossa, K. E. Toghill, V. Amstutz, H. H. Girault and M. Paolone, Macroscopic indicators of fault diagnosis and ageing in electrochemical double layer capacitors, Journal of Energy Storage, 2015, 2, 8-24.

38 M. A. Pope, S. Korkut, C. Punckt and I. A. Aksay, Supercapacitor Electrodes Produced through Evaporative Consolidation of Graphene Oxide-Water-Ionic Liquid Gels, J. Electrochem. Soc., 2013, 160, A1653-A1660.

39 R. I. J. Jaidev, A. K. Mishra and S. Ramaprabhu, Polyaniline$\mathrm{MnO}_{2}$ nanotube hybrid nanocomposite as supercapacitor electrode material in acidic electrolyte, J. Mater. Chem., 2011, 21, 17601.

40 N. Maheswari and G. Muralidharan, Controlled synthesis of nanostructured molybdenum oxide electrodes for high performance supercapacitor devices, Appl. Surf. Sci., 2017, 416, 461-469.

41 C. Huang, J. Zhang, N. P. Young, H. J. Snaith and P. S. Grant, Solid-state supercapacitors with rationally designed heterogeneous electrodes fabricated by large area spray processing for wearable energy storage applications, Sci. Rep., 2016, 6, 25684.

42 M. Cheng, L. Sun, G. Buja and L. Song, Advanced Electrical Machines and Machine-Based Systems for Electric and Hybrid Vehicles, Energies, 2015, 8, 9541-9564.

43 G. Jewell, in Symposium on Materials for a Sustainable Future, Birmingham, 2009, pp. 11-18.

44 L. Zhang, M. Ou, H. Yao, Z. Li, D. Qu, F. Liu, J. Wang, J. Wang and Z. Li, Enhanced supercapacitive performance of graphite-like $\mathrm{C}_{3} \mathrm{~N}_{4}$ assembled with NiAl-layered double hydroxide, Electrochim. Acta, 2015, 186, 292-301.

45 Q. Chen, Y. Zhao, X. Huang, N. Chen and L. Qu, Threedimensional graphitic carbon nitride functionalized graphene-based high-performance supercapacitors, $J$. Mater. Chem. A, 2015, 3, 6761-6766.

46 C. M Subramaniyam, K. A. Deshmukh, Z. Tai, N. Mahmood, A. D. Deshmukh, J. B. Goodenough, S. X. Dou and H. K. Liu, 2D Layered Graphitic Carbon Nitride Sandwiched with Reduced Graphene Oxide as Nanoarchitectured Anode for Highly Stable Lithium-ion Battery, Electrochim. Acta, 2017, 237, 69-77.

47 G. Xiong, C. Meng, R. G. Reifenberger, P. P. Irazoqui and T. S. Fisher, A Review of Graphene-Based Electrochemical Microsupercapacitors, Electroanalysis, 2014, 26, 30-51.

48 D. Jiang, Q. Xu, S. Meng, C. Xia and M. Chen, Construction of cobalt sulfide/graphitic carbon nitride hybrid nanosheet composites for high performance supercapacitor electrodes, J. Alloys Compd., 2017, 706, 41-47. 
49 S. X. Zhou, X. Y. Tao, J. Ma, L. T. Guo, Y. B. Zhu, H. L. Fan, Z. S. Liu and X. Y. Wei, Synthesis of flower-like PANI/g$\mathrm{C}_{3} \mathrm{~N}_{4}$ nanocomposite as supercapacitor electrode, Vacuum, 2018, 149, 175-179.

50 X. Chen, X. Zhu, Y. Xiao and X. Yang, PEDOT/g- $\mathrm{C}_{3} \mathrm{~N}_{4}$ binary electrode material for supercapacitors, J. Electroanal. Chem., 2015, 743, 99-104.
51 X. Chang, X. Zhai, S. Sun, D. Gu, L. Dong, Y. Yin and Y. Zhu, $\mathrm{MnO}_{2} / \mathrm{g}-\mathrm{C}_{3} \mathrm{~N}_{4}$ nanocomposite with highly enhanced supercapacitor performance, Nanotechnology, 2017, 28, 135705. 